Article

\title{
Functional Poly(dihalopentadiene)s: Stereoselective Synthesis, Aggregation-Enhanced Emission and Sensitive Detection of Explosives
}

\author{
Ting Han ${ }^{1,2}\left(\mathbb{D}\right.$, Yun Zhang ${ }^{1,2}$, Benzhao He ${ }^{1,2}$, Jacky W. Y. Lam ${ }^{1,2, *}$ and Ben Zhong Tang ${ }^{1,2,3, *}$ \\ 1 HKUST-Shenzhen Research Institute, No. 9 Yuexing 1st RD, South Area, Hi-tech Park, Nanshan, \\ Shenzhen 518057, China; thanac@ust.hk (T.H.); yzhangcl@connect.ust.hk (Y.Z.); hebenzhao@ust.hk (B.H.) \\ 2 Department of Chemistry, The Hong Kong Branch of Chinese National Engineering Research Center for \\ Tissue Restoration and Reconstruction, Institute for Advanced Study, Department of Chemical and \\ Biological Engineering and Division of Life Science, The Hong Kong University of Science and Technology, \\ Clear Water Bay, Kowloon, Hong Kong, China \\ 3 NSFC Center for Luminescence from Molecular Aggregates, SCUT-HKUST Joint Research Institute, \\ State Key Laboratory of Luminescent Materials and Devices, South China University of Technology, \\ Guangzhou 510640, China \\ * Correspondence: chjacky@ust.hk (J.W.Y.L.); tangbenz@ust.hk (B.Z.T.); Tel.: +852-2358-7375 (B.Z.T.)
}

Received: 3 July 2018; Accepted: 23 July 2018; Published: 25 July 2018

\begin{abstract}
The development of polymeric materials with novel structures and unique properties and functionalities is of both academic and industrial significance. In this work, functional poly(dihalopentadiene)s were synthesized by boron trihalide-mediated multicomponent polymerization routes in a stereoselective manner. The polymerizations of tetraphenylethylene-containing diyne, $\mathrm{BX}_{3}(\mathrm{X}=\mathrm{Cl}, \mathrm{Br})$ and $p$-tolualdehyde proceed smoothly in dichloromethane under mild conditions to afford high molecular weight poly(dihalopentadiene)s with a predominant $(Z, Z)$-configuration in moderate to good yields. The reaction conditions and the boron trihalide used were found to have great effects on the stereochemistry of the resulting polymer structures. The obtained poly(1,5-dihalo-(Z,Z)-1,4-pentadiene)s possess high thermal stability and good film-forming ability. Their thin films show high refractive index of 1.9007-1.6462 in a wide wavelength region of $380-890 \mathrm{~nm}$ with low optical dispersion. The polymers are weakly emissive in dilute solutions but become highly emissive upon aggregated, demonstrating a unique phenomenon of aggregation-enhanced emission. Their nanoaggregates in aqueous media can serve as sensitive fluorescent chemosensors for the detection of explosives with a superamplification effect and a low detection limit.
\end{abstract}

Keywords: multicomponent polymerization; stereoselectivity; aggregation-enhanced emission; explosive detection; high refractive index

\section{Introduction}

The construction of new functional polymers with unique structures and properties and potential high-tech applications is an enduring research topic in polymer science due to its great academic and industrial significance. Most of the commonly used functional polymers, such as polyolefins, polyesters and polyamides are constructed by the well-established homo- and two-component polymerizations [1,2]. However, these methods have become hard to meet the increasing demand on new polymeric materials with well-defined and complicated structures and multi-functionalities. Recently, multicomponent polymerizations (MCPs) derived from the fascinating multicomponent reactions (MCRs) [3-9] have received great attention and become a new research 
frontier in polymer science [10]. In MCPs, the reaction components are added into one reactor in one step or in a sequential/cascade manner without isolating the reactive intermediates $[11,12]$. From the synthetic point of view, MCPs generally have the merits of simple synthetic and isolation procedures, mild reaction condition, good functional-group tolerance, high efficiency, and free of waste formation. Furthermore, the simultaneous incorporation of three or more monomers with different functionalities in a one-pot $\mathrm{MCP}$ greatly enriches the structural diversity and properties of the resulting polymers [13-16].

The unique features of MCPs enable them to be effective tools for the preparation of functional polymers with complex and well-defined structures that are hard to be accessed by other polymerization approaches [17-22]. For example, a variety of heteroatom-rich polymers with multifunctionalities such as poly( $N$-sulfonylamidine)s [23-25], poly( $N$-sulfonylimidate)s [24,26,27], poly(iminocoumarin)s [28], poly(phosphorus amidine)s [29] and oxindole-containing poly( $\mathrm{N}$-acylsulfonamide)s [30] have been facilely and efficiently synthesized through the $\mathrm{Cu}(\mathrm{I})$-catalyzed one-pot MCPs of alkynes, sulfonyl azides and different nucleophiles. Sequence-controlled polymers have also been achieved by one-pot multi-step MCPs [25,31]. As some regio- and stereoselective MCRs have been developed and reported, regio- and stereoregular polymers are possible to be produced from the derived MCPs. For instance, inspired by the high regio- and stereoselectivity of MCRs of alkyne, carbonyl chloride, and secondary amines [32-36], our group have developed an efficient MCP of diyne, terephthaloyl chloride, and secondary aliphatic amines to synthesize functional poly(arylene enaminone)s with high content of $E$-configuration of up to $93 \%$ [37]. When the secondary amines were replaced by primary amines, regio- and stereoregular poly(enaminone)s with sole Z-configuration were generated in nearly quantitative yields [38]. The high regio- and stereoregularity of the polymer structure were attributed to the formation of strong intramolecular hydrogen bonds between the $\mathrm{C}=\mathrm{O}$ and $\mathrm{N}-\mathrm{H}$ groups in the resulting hydroamination products, which not only stablized the $Z$-configuration by blocking the $E / Z$ isomerization but also inhibited the enamine-imine tautomerization process. Despite of the rapid progress of MCPs in the past decade, examples of powerful MCPs toward regio-/stereoregular functional polymers are still limited possibly due to the lack of efficient MCRs with high chemo-/regio-/stereoselectivity.

Recently, an interesting boron trihalide $\left(\mathrm{BX}_{3}\right)$-mediated alkyne-aldehyde coupling reaction toward stereo-defined 1,3,5-triaryl-1,5-dihalo-1,4-pentadienes (Scheme 1) have attracted our great interest $[39,40]$. The stereoselectivity of this reaction can be well tuned by simply changing the reaction conditions or the type of $\mathrm{BX}_{3}$ employed. In the presence of boron trichloride $\left(\mathrm{BCl}_{3}\right)$, the reactions of aryl aldehydes with 2 equivalents of arylacetylenes afforded (E,Z)-1,4-pentadiene as a major product with a minor quantity of the $(Z, Z)$-isomer (Scheme 1 , route a) [39]. By controlling the reaction temperature and the sequence of reactant addition, $(Z, Z)-1,5$-dichloro-1,4-pentadiene was obtained as the major product (Scheme 1, route b) [40]. When boron tribromide $\left(\mathrm{BBr}_{3}\right)$ was used as the mediator at low temperature, the corresponding $(Z, Z)-1,3,5$-triaryl-1,5-dibromo-1,4-pentadienes were formed as the primary products in excellent yields (Scheme 1, route c) [39]. Previously, we have developed Scheme 1a into a metal-free MCP for the stereoselective construction of polymers with mainly (E,Z)-1,5-dichloro-1,4-pentadiene units (Scheme 2, route a) [41]. Due to our continuing interest in the development of new polymerization reactions to synthesize stereoregular functional polymers, herein we intend to further explore the possibility of developing the MCRs in Scheme $1 b, c$ into efficient stereoselective MCPs for the construction of poly(pentadiene)s with dominant $(Z, Z)$-isomeric structures.

By varying the polymerization conditions and the types of boron trihalide used, in this work, we successfully prepared two stereo-defined functional polymers with $(Z, Z)$-1,4-pentadiene as major segments (Scheme $2 b, c$ ) by the boron trihalide-mediated polycoupling reactions of tetraphenylethylene (TPE)-containing terminal diyne (1) and $p$-tolaldehyde (2). Polymer P1/2-I with $(Z, Z)-1,5$-dichloropentadiene as the major isomeric structure was obtained by changing the addition sequence of the reactants to allow the diyne monomer to react with $\mathrm{BCl}_{3}$ first in refluxed 
dichloromethane (DCM) (Scheme 2, route b). On the other hand, polymer P1/2-II dominated with $(Z, Z)-1,5$-dibromopentadiene unit was generated by replacing $\mathrm{BCl}_{3}$ with $\mathrm{BBr}_{3}$ at low polymerization temperature of $-40{ }^{\circ} \mathrm{C}$ (Scheme 2, route c). Both polymers possess excellent film-forming ability and their thin films show high refractive index and low chromatic dispersion. The TPE units of the polymers endow them with much stronger fluorescence in the aggregate state than in the solution state, showing an obvious aggregation-enhanced emission (AEE) property. Considering the significance of explosive detection in homeland security and antiterrorism, we also investigated the possibility of utilizing the fluorescent nanoaggregates of the obtained AEE polymers as fluorescent chemosensors for the sensitive detection of explosives.

(a)

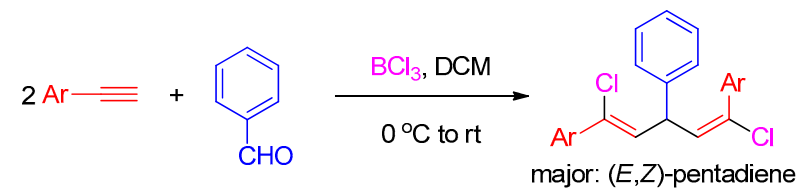

(b)

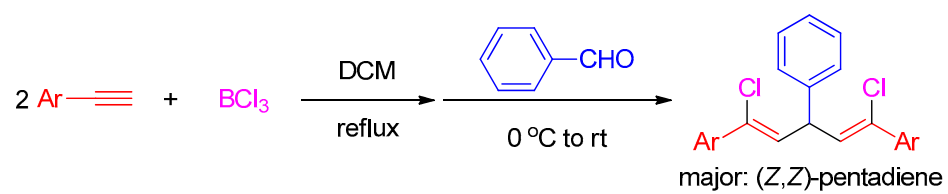

(c)

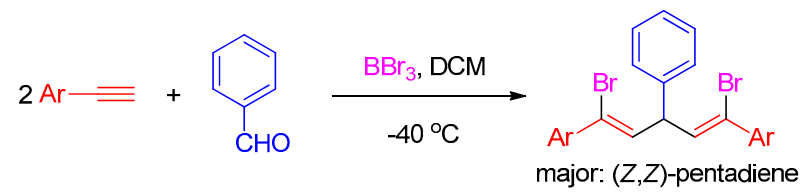

Scheme 1. Boron trihalide-mediated alkyne-aldehyde coupling reactions toward 1,5-dihalo-1,4-pentadienes with different stereochemistry: (a) $\mathrm{BCl}_{3}$-mediated alkyne-aldehyde reaction toward (E,Z)-1,5-dichloro-1,4-pentadiene; (b) $\mathrm{BCl}_{3}$ - and (c) $\mathrm{BBr}_{3}$-mediated alkyne-aldehyde reaction toward $(Z, Z)-1,5$-dichloro-1,4-pentadiene.

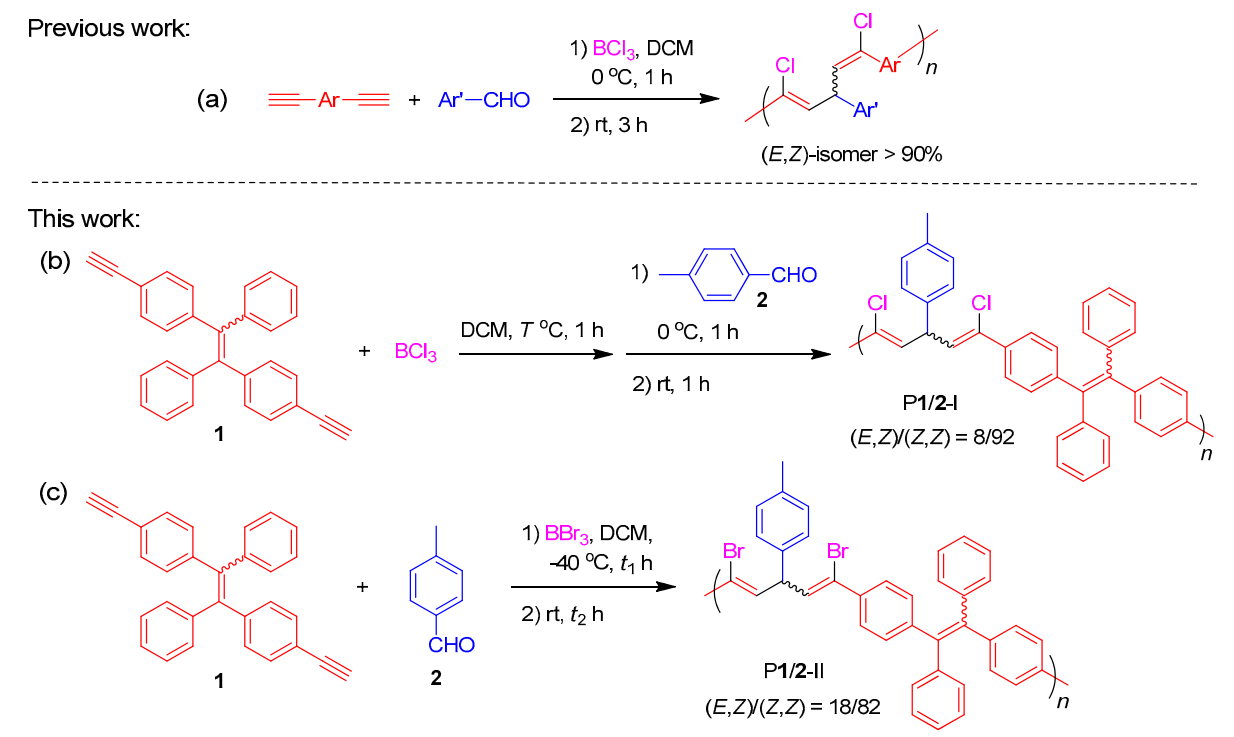

Scheme 2. Metal-free $\mathrm{BX}_{3}$-mediated multicomponent polymerizations (MCP) of alkyne and aldehyde toward stereo-defined poly(1,4-pentadiene)s: (a) $\mathrm{BCl}_{3}$-mediated MCP toward poly(1,4-pentadiene)s with dominant (E,Z)-isomeric structures; (b) $\mathrm{BCl}_{3}$ - and (c) $\mathrm{BBr}_{3}$-mediated $\mathrm{MCP}$ toward poly(1,4-pentadiene)s with dominant $(Z, Z)$-isomeric structures. 


\section{Experimental Section}

\subsection{Materials and Methods}

Monomer 1 was synthesized according to the reported procedures [42]. Monomer 2, $\mathrm{BCl}_{3}$, $\mathrm{BBr}_{3}$ and all other reagents used for monomer synthesis and polymerizations were purchased from Aldrich (Hong Kong, China) and used without further purification. Tetrahydrofuran (THF) was distilled from sodium benzophenone ketyl under nitrogen immediately prior to use. Dichloromethane (DCM) was purchased from Aldrich and distilled from molecular sieves under nitrogen prior to use. Weight-average molecular weights $\left(M_{\mathrm{W}}\right)$ and polydispersity indices (PDI) of the obtained polymers were estimated by a Waters gel permeation chromatography (GPC) system equipped with a Waters 515 HPLC pump (Waters, Hong Kong, China), a set of Styragel columns (HT3, HT4 and HT6; $M_{\mathrm{W}}$ range $10^{2}-10^{7}$ ), a column temperature controller, a Waters 486 wavelength-tunable UV-vis detector and a Waters 2414 differential refractometer (Waters, Hong Kong, China). THF was used as eluent at a flow rate of $1.0 \mathrm{~mL} / \mathrm{min}$. The column temperature was maintained at $40{ }^{\circ} \mathrm{C}$ and the working wavelength of the UV-vis detector was set at $254 \mathrm{~nm}$. A set of monodisperse polystyrene standards (Waters) covering a $M_{\mathrm{W}}$ range of $10^{3}-10^{7}$ were used for $M_{\mathrm{W}}$ calibration. The THF solutions of the polymer samples $(\sim 1 \mathrm{mg} / \mathrm{mL})$ used for GPC measurement were filtered through $0.45 \mu \mathrm{m}$ PTFE syringe-type filters before being injected into the GPC system. FT-IR spectra were recorded on a Bruker Vertex 70 FT-IR spectrometer using KBr disk (Bruker, Hong Kong, China). ${ }^{1} \mathrm{H}$ and ${ }^{13} \mathrm{C}$ NMR spectra were measured on a Bruker ARX 400 NMR spectrometer in deuterated chloroform (chloroform- $d$ ). Chemical shifts were calibrated using $\mathrm{CDCl}_{3}$ as internal reference at $\delta 7.26\left({ }^{1} \mathrm{H}\right.$ NMR) and $\delta 77.16\left({ }^{13} \mathrm{C}\right.$ NMR). Thermogravimetric analysis (TGA) was carried on a Perkin-Elmer TGA 7 analyzer (PerkinElmer, Hong Kong, China) at a heating rate of $10{ }^{\circ} \mathrm{C} / \mathrm{min}$ under nitrogen. UV-vis spectra and photoluminescence (PL) spectra were recorded on a PerkinElmer Lambda 365 UV/Vis spectrophotometer and a Horiba Fluorolog spectrophotometer (Horiba, Hong Kong, China), respectively. Fluorescence quantum yields were measured using a Hamamatsu absolute PL quantum yield spectrometer C11347 Quantaurus_QY (Hamamatsu Photonics, Hong Kong, China). Refractive indices (RI or $n$ ) were determined on a J.A. Woollam Variable Angle Ellipsometer (J.A. Woollam, Hong Kong, China), with a model of Alpha-SE and a wavelength tunability from 380 to $890 \mathrm{~nm}$. The polymer thin films for RI measurement were prepared by spin-coating the 1,2-dichloroethane solutions of polymer samples $(\sim 10 \mathrm{mg} / \mathrm{mL})$ at $1000 \mathrm{rpm}$ for $1 \mathrm{~min}$ on silicon wafers and then dried in a vacuum oven at room temperature overnight.

\subsection{Polymerization}

Preparation procedures of P1/2-I: Into a $15 \mathrm{~mL}$ Schlenk tube with a stirring bar was added diyne $1(0.20 \mathrm{mmol}, 76 \mathrm{mg})$. The tube was evacuated under vacuum and then flushed with nitrogen for three cycles. Afterward, $2 \mathrm{~mL}$ of distilled DCM was injected into the tube followed by the dropwise addition of a solution of $\mathrm{BCl}_{3}$ in hexane $(1.0 \mathrm{M}, 0.22 \mathrm{~mL}, 0.22 \mathrm{mmol})$ under nitrogen. The reaction mixture was heated to $45^{\circ} \mathrm{C}$ and refluxed for $1 \mathrm{~h}$ under stirring. Then the reaction tube was cooled to $0{ }^{\circ} \mathrm{C}$ using an ice bath and $p$-tolualdehyde $2(0.20 \mathrm{mmol}, 23.6 \mu \mathrm{L})$ was added into the reaction system under the protection of nitrogen gas. The solution mixture was first stirred at $0{ }^{\circ} \mathrm{C}$ for $1 \mathrm{~h}$ and then warmed to room temperature to stir for another $1 \mathrm{~h}$. The reaction mixture was then quenched by a small amount of water with continuous stirring and diluted with THF. Subsequently, the resulting solution was added dropwise to a $200 \mathrm{~mL}$ of methanol via a cotton filter under vigorous stirring. The precipitates were allowed to stand overnight before being collected by filtration and washed with methanol and hexane. The obtained polymer was dried under vacuum at room temperature to a constant weight. Characterization data: yellow powder; yield $68 \% . M_{\mathrm{w}}: 119,700 ; M_{\mathrm{w}} / M_{\mathrm{n}}: 3.9$ (GPC, polystyrene calibration). IR (KBr), $v\left(\mathrm{~cm}^{-1}\right)$ : 3051, 3023, 2921, 2860, 2818, 1946, 1898, 1802, 1686, 1599, $1503,1443,1402,1308,1243,1186,1075,1019 .{ }^{1} \mathrm{H}$ NMR (CDCl $\left.3,400 \mathrm{MHz}\right), \delta$ (ppm): 7.35-6.98, 6.27, 5.36, 2.32. ${ }^{13} \mathrm{C} \mathrm{NMR}\left(\mathrm{CDCl}_{3}, 100 \mathrm{MHz}\right), \delta$ (ppm): 144.29, 143.49, 143.35, 140.78, 138.47, 137.76, 137.52, 
$136.59,135.68,133.91,131.44,131.39,129.61,129.41,128.06,127.86,127.42,127.24,126.94,126.68,126.11$, $125.91,45.60,21.18$.

P1/2-II: To a $15 \mathrm{~mL}$ Schlenk tube with a stirring bar was added diyne $1(0.20 \mathrm{mmol}, 76 \mathrm{mg})$. A vacuum-nitrogen cycle was then performed three times before $2 \mathrm{~mL}$ of distilled DCM was injected by syringe followed by the addition of $p$-tolualdehyde $2(0.20 \mathrm{mmol}, 23.6 \mu \mathrm{L})$. Subsequently, the mixture was cooled to $-40^{\circ} \mathrm{C}$ in a dry ice/acetonitrile cooling bath and the solution of $\mathrm{BBr}_{3}$ in $\mathrm{DCM}(1.0 \mathrm{M}$, $0.22 \mathrm{~mL}, 0.22 \mathrm{mmol}$ ) was then dropwise added into the mixture. The solution was stirred at $-40{ }^{\circ} \mathrm{C}$ for $2 \mathrm{~h}$ and then warmed to room temperature and stirred for another $1 \mathrm{~h}$. The reaction mixture was then terminated by adding a small amount of water and diluted with THF. The resulting solution was then added dropwise to a $200 \mathrm{~mL}$ of methanol via a cotton filter with vigorous stirring to precipitate the polymeric products. The precipitates were allowed to stand overnight and then collected after filtration, washing with methanol and hexane and dried under vacuum at room temperature to a constant weight. Characterization data: brownish yellow powder; yield 79\%. $M_{\mathrm{w}}: 63,100 ; M_{\mathrm{w}} / M_{\mathrm{n}}$ : 4.3 (GPC, polystyrene calibration). IR (KBr), $v\left(\mathrm{~cm}^{-1}\right)$ : 3051, 3022, 2920, 2860, 2818, 1946, 1899, 1685, $1599,1510,1492,1443,1403,1356,1267,1182,1111,1074,1019 .{ }^{1} \mathrm{H}$ NMR $\left(\mathrm{CDCl}_{3}, 400 \mathrm{MHz}\right), \delta$ (ppm): 7.31-7.00, 6.38, 5.25, 2.32. $\left.{ }^{13} \mathrm{C} \mathrm{NMR} \mathrm{(CDCl} 3,100 \mathrm{MHz}\right), \delta$ (ppm): 144.30, 143.54, 143.33, 140.75, 137.98, $137.44,137.33,136.69,131.45,131.33,129.63,128.57,128.06,127.85,127.46,127.25,127.07,126.95,126.87$, $51.31,21.19$.

To assist the structural characterization of P1/2-I and P1/2-II, polymer P1/2 was synthesized by the polymerization route shown in Scheme $2 \mathrm{a}$ and Scheme S1 using TPE-containing diyne 1, $p$-tolualdehyde 2 and $\mathrm{BCl}_{3}$ as reactants. According the reported procedures in the literature [41], $1(0.2 \mathrm{mmol}, 76.0 \mathrm{mg})$ was first added into a $15 \mathrm{~mL}$ Schlenk tube equipped with a stirring bar and then the tube was evacuated under vacuum and flushed with dry nitrogen for three times. Subsequently, $2 \mathrm{~mL}$ of distilled DCM and aldehyde $2(0.20 \mathrm{mmol}, 23.6 \mu \mathrm{L})$ were injected into the reaction system under nitrogen atmosphere. The mixture was then cooled to $0{ }^{\circ} \mathrm{C}$ followed by the dropwise addition of $0.22 \mathrm{~mL}$ of $\mathrm{BCl}_{3}$ solution $(1.0 \mathrm{M}$ in hexane, $0.22 \mathrm{mmol})$. The solution mixture was stirred at $0{ }^{\circ} \mathrm{C}$ under nitrogen for $1 \mathrm{~h}$ and then was warmed to room temperature to stir for another $3 \mathrm{~h}$. After the reaction mixture was quenched with water and diluted with THF, the resulting solution was added dropwise to a $200 \mathrm{~mL}$ of methanol via a cotton filter under vigorous stirring. The precipitates were collected by filtration, washing with methanol and hexane, and then drying under vacuum at room temperature to a constant weight. IR (KBr), $v\left(\mathrm{~cm}^{-1}\right)$ : 3076, 3052, 3023, 2922, 2861, 1946, 1898, 1798, $1685,1623,1599,1503,1441,1401,1349,1308,1242,1184,1113,1074,1019 .{ }^{1} \mathrm{H}$ NMR $\left(\mathrm{CDCl}_{3}, 400 \mathrm{MHz}\right)$,

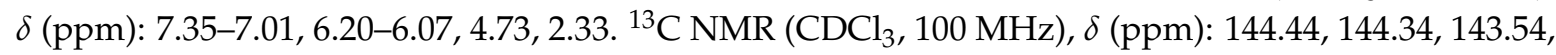
143.34, 143.17, 141.02, 140.74, 138.73, 136.69, 135.49, 135.00, 134.89, 133.36, 132.63, 131.45, 131.28, 129.64, $129.13,128.46,128.25,128.07,128.01,127.86,127.24,126.96,126.82,125.86,45.47,21.17$.

\subsection{Preparation of Model Compounds}

The model compounds (3-5) were prepared according to the literature methods [39,40]. Their characterization data are given as follows.

1,5-Dichloro-1,5-diphenyl-3-(p-tolyl)-(E,Z)-1,4-pentadiene (3) [39]: ${ }^{1} \mathrm{H}$ NMR $\left(\mathrm{CDCl}_{3}, 400 \mathrm{MHz}\right)$ : $\delta 7.58-7.15(\mathrm{~m}, 14 \mathrm{H}), 6.26(\mathrm{~d}, 1 \mathrm{H}, J=9.2 \mathrm{~Hz}), 6.18(\mathrm{~d}, 1 \mathrm{H}, J=10.6 \mathrm{~Hz}), 4.84(\mathrm{t}, 1 \mathrm{H}, J=10.0 \mathrm{~Hz})$, $2.33(\mathrm{~s}, 3 \mathrm{H}) .{ }^{13} \mathrm{C} \mathrm{NMR}\left(\mathrm{CDCl}_{3}, 100 \mathrm{MHz}\right): \delta 138.5,137.6,136.7,136.6,133.5,132.8,129.5,129.2,128.9$, $128.8,128.3,127.8,127.1,126.5,45.2,21.0$.

1,5-Dichloro-1,3,5-triphenyl-(Z,Z)-1,4-pentadiene (4) [40]: ${ }^{1} \mathrm{H}$ NMR (chloroform- $d$ ): $\delta 7.63-7.24(\mathrm{~m}, 15 \mathrm{H})$, $6.34(\mathrm{~d}, 2 \mathrm{H}, J=9.0 \mathrm{~Hz}), 5.47(\mathrm{t}, 1 \mathrm{H}, J=9.0 \mathrm{~Hz}) .{ }^{13} \mathrm{C}$ NMR (chloroform- $d$ ): $\delta 141.3,137.7,134.3,128.8$, $128.7,128.3,127.4,127.3,126.9,126.6,45.7$.

1,5-Dibromo-1,5-diphenyl-3-(p-tolyl)-(Z,Z)-1,4-pentadiene (5) [39]: ${ }^{1} \mathrm{H}$ NMR ( $\left.\mathrm{CDCl}_{3}, 400 \mathrm{MHz}\right)$ :

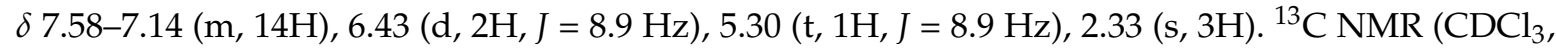
$100 \mathrm{MHz}): \delta 139.6,137.8,136.5,131.2,129.5,128.7,128.2,127.7,127.3,126.8,51.0,21.0$. 


\section{Results and Discussion}

\subsection{Polymer Synthesis}

In order to develop the MCRs shown in Scheme $1 b, c$ into polymerization tools for the construction of functional polymers with dominant $(Z, Z)-1,4$-pentadiene isomeric structures, terminal diyne 1 with TPE moiety was first synthesized according to the literature [42]. To obtain soluble polymers with high molecular weights, the derived $\mathrm{BX}_{3}$-mediated polymerizations of $\mathbf{1}$ and $p$-tolualdehyde $\mathbf{2}$ were carried out under different conditions and the polymerization results were summarized in Tables 1 and 2.

In our previous work, we have systematically studied the key parameters involved in the multicomponent polymerization of 1,2 and $\mathrm{BCl}_{3}$ for the synthesis of $\mathrm{P} 1 / 2$ with $(E, Z)$-diene as major structural segments [41]. The best polymerization result was obtained by first reacting in DCM at $0{ }^{\circ} \mathrm{C}$ for $1 \mathrm{~h}$ followed by a further reaction at room temperature for $3 \mathrm{~h}$ at a monomer concentration of [1]:[2]: $\left[\mathrm{BCl}_{3}\right]=0.1: 0.1: 0.11$. Based on the experience in the synthesis of P1/2 (Scheme S1) and the small molecular reactions shown in Scheme $1 \mathrm{~b}$, herein we tried to react 1 with $\mathrm{BCl}_{3}$ in $\mathrm{DCM}$ at a reflux temperature prior to coupling with 2 at $0{ }^{\circ} \mathrm{C}$. At first, the reflux temperature was set as $T=55^{\circ} \mathrm{C}$ and the reaction mixture of $\mathbf{1}$ and $\mathrm{BCl}_{3}$ was stirred at this temperature for $1 \mathrm{~h}$ followed by the addition of 2 at $0^{\circ} \mathrm{C}$. After stirring at $0^{\circ} \mathrm{C}$ for $1 \mathrm{~h}$ and at room temperature for another $1 \mathrm{~h}$, an insoluble gel was, however, formed (Table 1 , no. 1). We then decreased the reflux temperature to $T=45^{\circ} \mathrm{C}$ while keeping other polymerization conditions unchanged (Table 1, no. 2). Under such conditions, soluble P1/2-I with a high molecular weight of 119,700 was obtained in a satisfactory yield (68\%). Regarding the $\mathrm{BBr}_{3}$-mediated alkyne-aldehyde coupling reaction (Scheme 1c), the derived polymerization of 1 and 2 was first carried out at $-40{ }^{\circ} \mathrm{C}$ due to the reported high reaction efficiency of the bromination process of aryl aldehydes by tribromoborane $[39,43]$. Upon the addition of $\mathrm{BBr}_{3}$ to the DCM solution of 1 and 2 at $-40^{\circ} \mathrm{C}$, the reaction was kept stirring at the same temperature for $4 \mathrm{~h}\left(t_{1}=4 \mathrm{~h}\right)$. However, only oligomers with a molecular weight of 6900 were collected (Table 2, no. 1). We then allowed the polymerization to react for an extra hour at room temperature $\left(t_{2}=1 \mathrm{~h}\right)$, but gelation process occurred under this condition (Table 2, no. 2). These results suggest that the reaction could be readily triggered at $-40{ }^{\circ} \mathrm{C}[39,40]$ and the polymer chains grow faster at room temperature. When the reaction time at $-40{ }^{\circ} \mathrm{C}$ was shortened to $2 \mathrm{~h}\left(t_{1}=2 \mathrm{~h}\right)$, a soluble polymer P1/2-II with a high molecular weight of 63,100 was afforded in a good yield of $79 \%$ (Table 2, no. 3). Further decreasing $t_{1}$ to $1 \mathrm{~h}$ lead to a slightly lower molecular weight and isolated yield (Table 2, no. 4).

Table 1. $\mathrm{BCl}_{3}$-mediated polymerizations of $\mathbf{1}$ and $\mathbf{2}$ at different temperatures.

\begin{tabular}{ccccc}
\hline No. & $T\left({ }^{\circ} \mathrm{C}\right)$ & Yield (\%) & $\boldsymbol{M}_{\mathbf{w}}{ }^{\mathrm{b}}$ & $\boldsymbol{M}_{\mathbf{w}} / \boldsymbol{M}_{\mathbf{n}}{ }^{\mathbf{b}}$ \\
\hline $1^{\mathrm{a}}$ & 55 & gel & & \\
$2^{\mathrm{a}}$ & 45 & 68 & 119,700 & 3.9 \\
\hline
\end{tabular}

a Reactions were carried out under the following conditions: $\mathbf{1}$ and $\mathrm{BCl}_{3}\left(1.0 \mathrm{M}\right.$ in hexane) were reacted at $T{ }^{\circ} \mathrm{C}$ in DCM under nitrogen for $1 \mathrm{~h}$. Monomer 2 was then added at $0{ }^{\circ} \mathrm{C}$ and the reaction mixture was kept at $0{ }^{\circ} \mathrm{C}$ for $1 \mathrm{~h}$. After being warmed to room temperature, the reaction was continued for another $1 \mathrm{~h}$. $[1]=[2]=0.2 \mathrm{M},\left[\mathrm{BCl}_{3}\right]=1.1$ $[1] ;{ }^{b}$ Determined by GPC in THF on the basis of a linear polystyrene calibration.

Table 2. $\mathrm{BBr}_{3}$-mediated polymerizations of $\mathbf{1}$ and $\mathbf{2}$ under different conditions.

\begin{tabular}{cccccc}
\hline No. & $\boldsymbol{t}_{\mathbf{1}}(\mathbf{h})$ & $\boldsymbol{t}_{\mathbf{2}}(\mathbf{h})$ & Yield (\%) & $\boldsymbol{M}_{\mathbf{w}} \mathbf{b}$ & $\boldsymbol{M}_{\mathbf{w}} / \boldsymbol{M}_{\mathbf{n}}{ }^{\mathbf{b}}$ \\
\hline $1^{\mathrm{a}}$ & 4 & 0 & 67 & 6900 & 2.3 \\
$2^{\mathrm{b}}$ & 4 & 1 & gel & & \\
$3^{\mathrm{b}}$ & 2 & 1 & 79 & 63,100 & 4.3 \\
$4^{\mathrm{b}}$ & 1 & 1 & 77 & 47,500 & 3.6 \\
\hline
\end{tabular}

a Reactions were carried out under the following conditions: 1, 2 and $\mathrm{BBr}_{3}(1.0 \mathrm{M}$ in DCM) were reacted in $\mathrm{DCM}$ under nitrogen at $-40{ }^{\circ} \mathrm{C}$ for $t_{1} \mathrm{~h}$ first. After being warmed to room temperature, the reaction was continued for another $t_{2} \mathrm{~h}$. $[1]=[2]=0.2 \mathrm{M},\left[\mathrm{BBr}_{3}\right]=1.1[1]{ }^{\mathrm{b}}$ Determined by GPC in THF on the basis of a linear polystyrene calibration. 


\subsection{Structural Characterization}

To assist the structural characterization of the obtained polymers, stereoregular poly[1,5-dichloro-(E,Z)-1,4-pentadiene] P1/2 was prepared according to the literature method (Scheme S1) [41]. The characterization data of compounds 3, 4 and 5 (Scheme 3) reported by Kabalka and co-workers $[39,40]$ were utilized to assist further analysis on the stereochemistry of P1/2, P1/2-I and P1/2-II, respectively.<smiles>Cc1ccc(C(/C=C(/Cl)c2ccccc2)/C(Cl)=C/c2ccccc2)cc1</smiles><smiles>ClC(=CC(C=C(Cl)c1ccccc1)c1ccccc1)c1ccccc1</smiles><smiles>C/C(=C/C(Br)c1ccccc1)c1ccc(C)cc1</smiles>

Scheme 3. Chemical structures of model compounds 3, 4 and 5.

As indicated by the ${ }^{1} \mathrm{H}$ NMR results of model compound 3 (see the Experimental section) and P1/2 (Figure 1a), the vinyl protons of the 1,5-dichloro-(E,Z)-1,4-pentadiene show two resonance peaks due to their slight difference in the chemical environment. The vinyl proton "a" of $Z$-configuration resonates at a relatively lower field of $\delta 6.26$ than that of $E$-configuration $\left(" b^{\prime \prime} ; \delta 6.18\right)$. Meanwhile, the resonance peak of the methyne proton " $\mathrm{c}$ " of P1/2 was observed at $\delta 4.84$ in Figure 1a accompanied with an almost invisible peak at $\delta \sim 5.30$. By comparing with the characterization results of $\mathbf{3}$ and $\mathbf{4}$, the peaks at $\delta 4.84$ and $\delta 5.30$ are attributed to the resonances of the $(E, Z)$ - and $(Z, Z)$-1,4-pentadiene units, respectively. By integrating the " $c$ " peak and the tiny peak at $\delta 5.30$, the ratio of $(E, Z)$ - to $(\mathrm{Z}, \mathrm{Z})$-conformers in P1/2 was calculated to be 95/5.

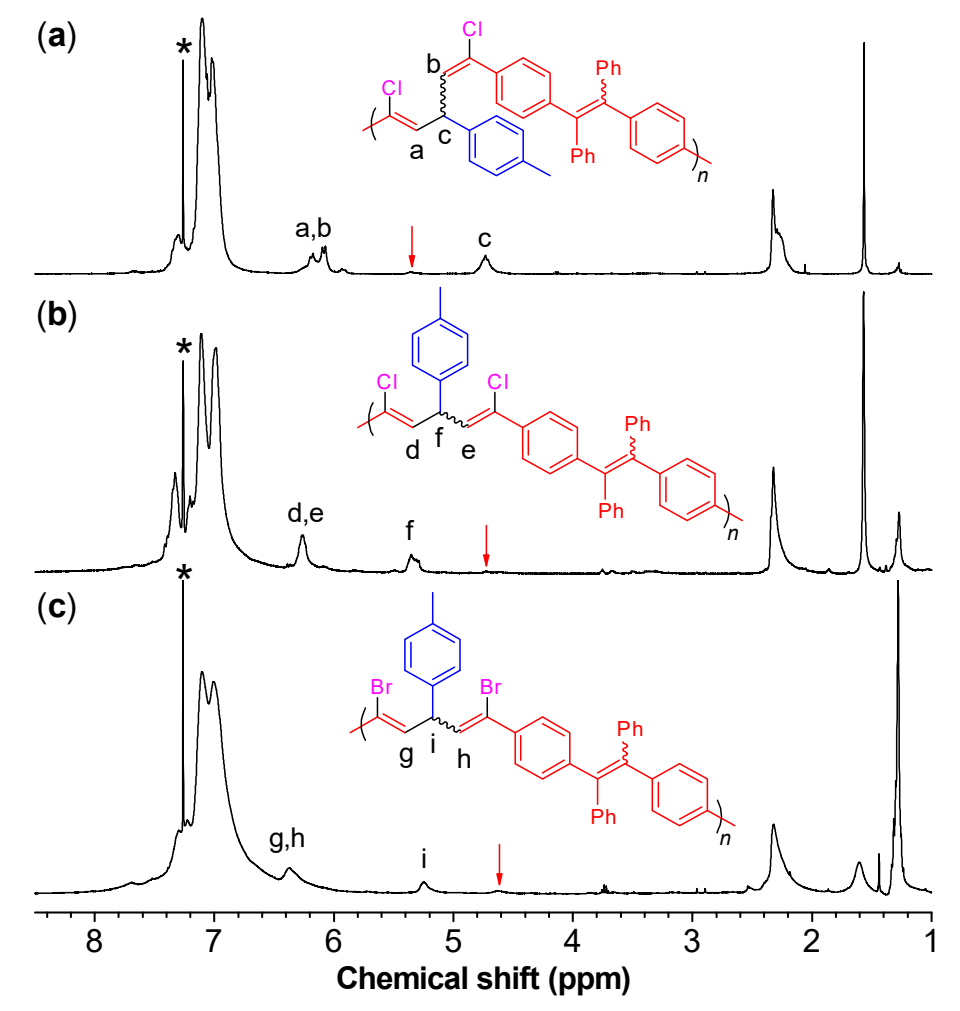

Figure 1. ${ }^{1} \mathrm{H}$ NMR spectra of (a) P1/2; (b) P1/2-I (Table 1, no. 2) and (c) P1/2-II (Table 2, no. 3) in chloroform- $d$. The peaks related to chloroform- $d$ are marked with asterisks. 
On the other hand, the vinyl protons of 1,5-dihalo-(Z,Z)-1,4-pentadiene (4 and 5) show only one resonance peak due to their symmetric structures. The vinyl protons of 4 resonate at $\delta 6.34$, while the peak of its methyne proton emerges at $\delta$ 5.47. In the ${ }^{1} \mathrm{H}$ NMR spectrum of P1/2-I as shown in Figure $1 \mathrm{~b}$, a sole peak corresponding to the absorption of the two vinyl protons of 1,5-dicloro-(Z,Z)-1,4-pentadiene skeleton (" $\mathrm{d}$ " and " $\mathrm{e}$ ") of P1/2-I was observed at $\delta 6.27$, which is consistent with the characterization result of 4 . The signal of the methyne proton " $\mathrm{f}$ " of P1/2-I, on the other hand, was observed at $\delta 5.35$ in Figure $1 \mathrm{~b}$ accompanied with an almost invisible peak at $\delta 4.73$. By integrating the " $\mathrm{f}$ " peak and this tiny peak, the ratio of $(Z, Z)$ - to $(E, Z)$-conformers was calculated to be $92 / 8$. Similarly, the vinyl protons and methyne proton of 1,5-dibromo- $(Z, Z)-1,4$-pentadiene (5) resonates at $\delta 6.43$ and $\delta 5.30$, respectively. Correspondingly, the ${ }^{1} \mathrm{H}$ NMR spectrum of P1/2-II shows a single broad peak related to the absorption of the two vinyl protons of the 1,5-dibromo-(Z,Z)-1,4-pentadiene skeleton (" $\mathrm{g}$ " and " $\mathrm{h}$ ") at $\delta 6.37$ (Figure 1c). The resonance peak of the methyne proton " $\mathrm{i}$ " locates at $\delta 5.25$ with a minor peak at $\delta 4.63$. The ratio of $(Z, Z)$ - to $(E, Z)$-conformers of P1/2-II was calculated to be $82 / 18$. These results clearly suggest that P1/2-I and P1/2-II are predominantly composed of $(Z, Z)-1,4$-pentadiene units.

Analysis by ${ }^{13} \mathrm{C}$ NMR further support the conclusion drawn from the ${ }^{1} \mathrm{H}$ NMR results. As shown in Figure 2, an obvious resonance peak at $\delta 45.4,45.5$, and 51.2 was observed in the ${ }^{13} \mathrm{C}$ NMR spectrum of P1/2, P1/2-I, and P1/2-II, respectively. This result is consistent with the characteristic resonance signal of the methyne carbon of 1,5-dichloro-(E,Z)-1,4-pentadiene (3), 1,5-dichloro-( $Z, Z)-1,4$-pentadiene (4), and 1,5-dibromo-( $Z, Z)-1,4$-pentadiene (5), which appears at $\delta 45.2,45.7$, and 51.0, respectively [39,40]. The structure of P1/2 has been fully confirmed in our previous publication by comparing its characterization results with those of the monomers and model compound 3 [41]. As the IR and NMR spectra of P1/2-I and P1/2-II largely resemble those of $\mathrm{P} 1 / 2$ apart from the above-mentioned difference induced by isomeric structures, they should contain the same 1,3,5-triaryl-1,5-dihalo-1,4-pentadiene units but with $(Z, Z)$-configuration as the predominant structure.

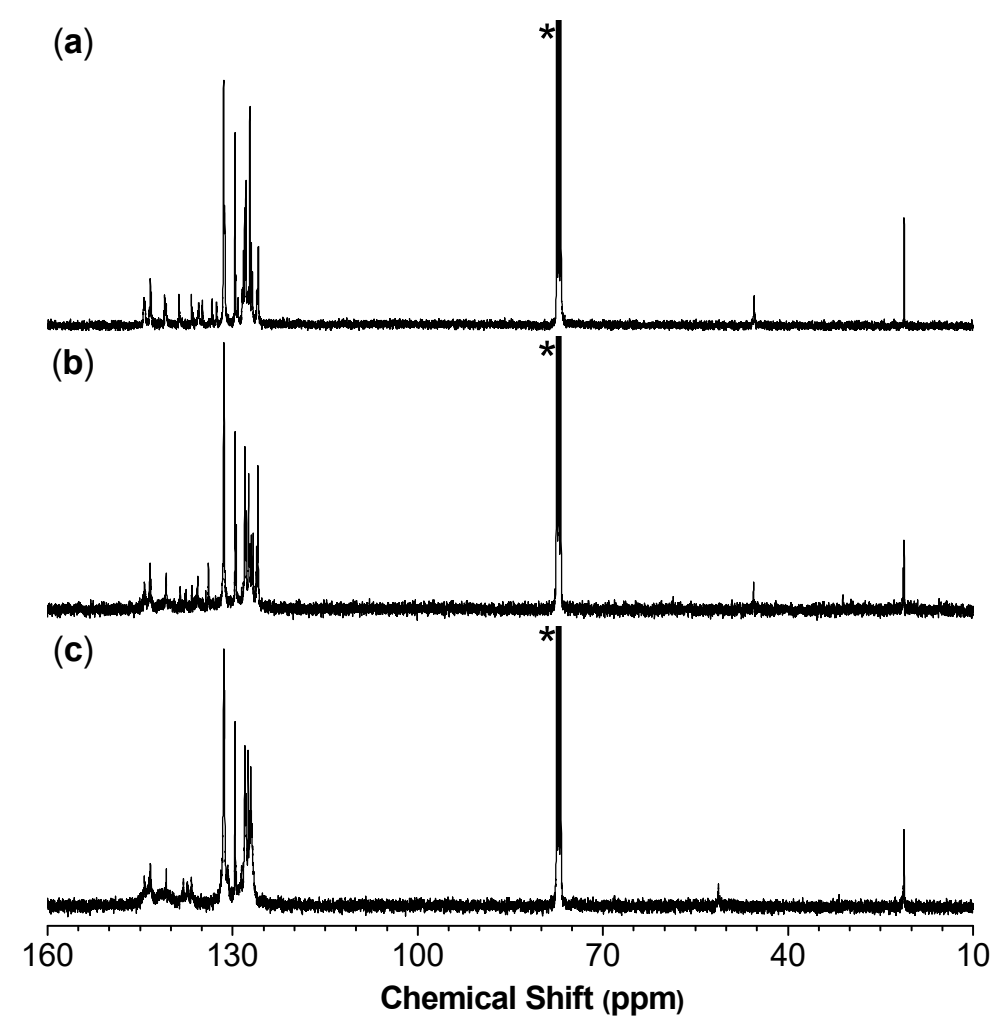

Figure 2. ${ }^{13} \mathrm{C}$ NMR spectra of (a) P1/2; (b) P1/2-I (Table 1, no. 2) and (c) P1/2-II (Table 2, no. 3) in chloroform- $d$. The peaks related to chloroform- $d$ are marked with asterisks. 


\subsection{Solubility and Thermal Stability}

The twisted conformation of the TPE moieties and the flexible 1,4-pentadiene structures endow P1/2-I and P1/2-II with good solubility in common organic solvents, such as THF, DCM, chloroform, and 1,2-dichloroethane. The thermal stability of the obtained polymers was evaluated by TGA under nitrogen. The results shown in Figure 3 suggest that P1/2-I and P1/2-II exhibit excellent thermal stability, losing merely $5 \%$ of their weights at a high temperature $\left(T_{\mathrm{d}}\right)$ of $341^{\circ} \mathrm{C}$ and $357^{\circ} \mathrm{C}$, respectively. It is worth noting that P1/2-II retains more than $60 \%$ of its original weight after being heated to $800{ }^{\circ} \mathrm{C}$ under nitrogen. The high $T_{\mathrm{d}}$ and char yield of P1/2-I and P1/2-II enable them to find potential high-tech applications as heat-resistant materials [44-46].

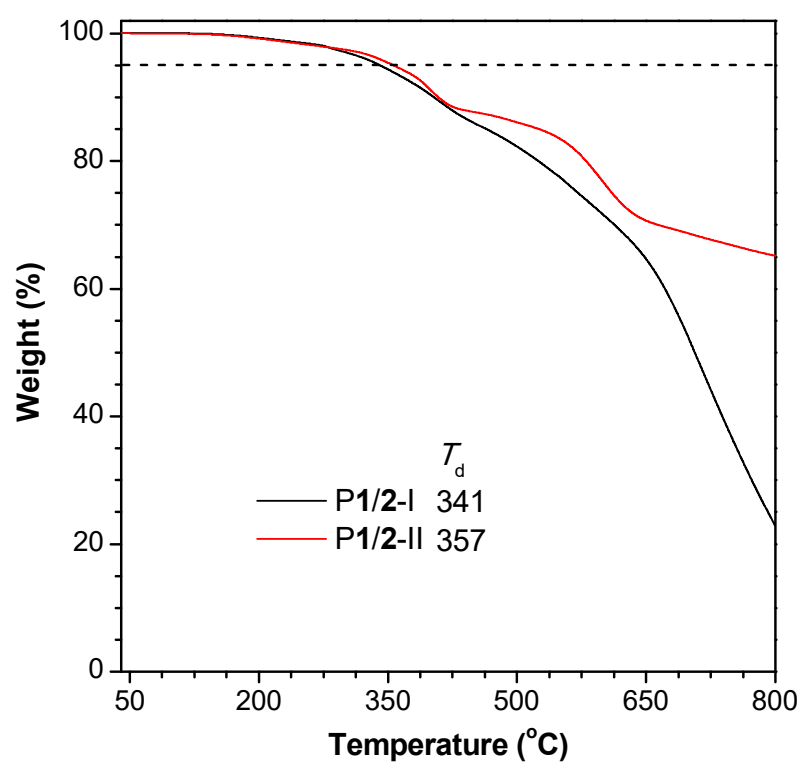

Figure 3. TGA thermograms of P1/2-I and P1/2-II recorded under nitrogen at a heating rate of $10{ }^{\circ} \mathrm{C} / \mathrm{min} . T_{\mathrm{d}}$ represents the degradation temperature for $5 \%$ weight loss.

\subsection{Light Refraction and Chromatic Dispersion}

Processable polymeric materials with high refractive index $(n)$ are in great demand due to their potential applications in the fabrication of advanced photonic and optoelectronic devices [47,48]. For instance, the $n$ value of polymer microlens used for image sensors of complementary metal oxide semiconductor often exceeds 1.70 or even 1.80 [47]. However, typical $n$ values of conventional optical plastics such as polystyrene, poly(methyl methacrylate) and polycarbonate generally fall in the range of 1.30-1.59 [49], which prevent them to be applied as advanced optical materials. Theoretically, polymers with aromatic rings and halogen atoms tend to show high $n$ values $[47,48,50]$. Therefore, P1/2-I and P1/2-II are likely to be high- $n$ materials. The good solution-processability and film-forming ability of these two polymers enable us to investigate the light refraction of their thin films. Tough polymer thin films can be readily fabricated by spin-coating their 1,2-dichloroethane solutions on silica wafers. The results shown in Figure 4 reveal that both P1/2-I and P1/2-II exhibit high $n$ values of $1.9007-1.6753$ and $1.8570-1.6462$, respectively, in a wide wavelength region of $380-890 \mathrm{~nm}$. The $n$ value of P1/2-I and P1/2-II at $632.8 \mathrm{~nm}$ is 1.6655 and 1.6913, respectively, which is much higher than those of conventional optical plastics. The relatively higher $n$ values of P1/2-II than P1/2-I can be explained by the intrinsically higher molar refraction of bromine than chloride atom [47].

In addition to refractive index, chromatic dispersion $(D)$ is another critical parameter for optical materials [51]. $D$ is defined as the reciprocal of Abbé number $\left(v_{\mathrm{D}}\right)$ and reflects the wavelength dependence of the $n$ values of a material [52]. For an optical material to be used in practical applications such as serving as lenses for ophthalmological application, both high $n$ values and low $D$ (or high 
$\left.v_{\mathrm{D}}\right)$ are required [53]. As illustrated in Figure 4, both P1/2-I and P1/2-II show a similarly low optical dispersion. Their $v_{\mathrm{D}}$ value is 11.7991 and 11.9576 , respectively, and the corresponding $D$ value is 0.0848 and 0.0836 , respectively.

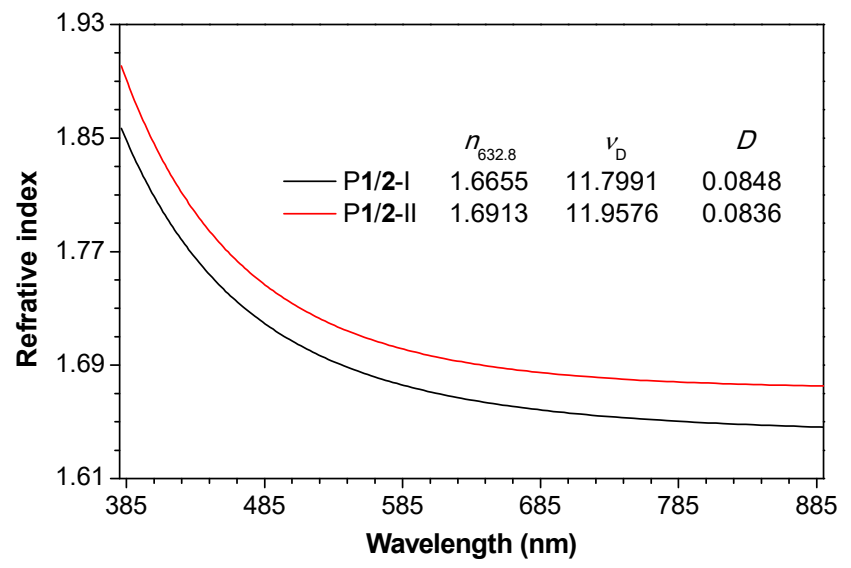

Figure 4. Wavelength dependence of refractive indices of thin films of P1/2-I and P1/2-II. Abbreviation: $n=$ refractive index, $v_{\mathrm{D}}=$ Abbé number $=\left(n_{\mathrm{D}}-1\right) /\left(n_{\mathrm{F}}-n_{\mathrm{C}}\right)$, where $n_{\mathrm{D}}, n_{\mathrm{F}}$ and $n_{\mathrm{C}}$ are the RI values at wavelengths of 589.2, 486.1 and $656.3 \mathrm{~nm}$, respectively, $D=$ chromatic dispersion $=1 / \nu_{\mathrm{D}}$.

\subsection{Aggregation-Enhanced Emission}

Luminescent polymeric materials with smart features have attracted tremendous interest due to their wide applications in bio-imaging, optical data storage, fluorescent chemo-/biosensors, light-emitting devices, etc. [54-59]. Conventional luminescent polymers are often composed of chromophores with large planar conformation. Such a structural feature often leads to the problem of emission quenching in the solid or aggregate state to greatly limit their practical applications [60]. In 2001, our group proposed a concept of aggregation-induced emission (AIE), which is the exact opposite of the aforementioned aggregation-caused quenching effect [61]. Luminogens with AIE attributes (AIEgens) are non-emissive in dilute solutions but become highly emissive upon aggregate formation [62,63]. The unique AIE effect enables AIE-active polymers to find various high-tech applications as thin films or in aqueous media [64-66].

TPE is a well-known AIEgen [67]. Therefore, the obtained TPE-containing polymers P1/2-I and P1/2-II are also anticipated to be AIE-active. The absorption spectra of these two polymers in THF were first measured before studying their photoluminescence (PL) properties. As depicted in Figure S1, P1/2-I and P1/2-II exhibit a similar absorption spectral pattern with an absorption maximum at $340 \mathrm{~nm}$ due to their similar molecular structures. To verify whether they are the AIE-active, we systematically studied their PL behaviors in THF/water mixtures with different water fractions $\left(f_{\mathrm{w}}\right)$. The results shown in Figure 5 and Figure S2 suggest that the present polymers P1/2-I and P1/2-II show a phenomenon of aggregation-enhanced emission (AEE). As shown in Figure 5a,b, the dilute THF solution of P1/2-I is weakly emissive. However, its PL intensity is gradually enhanced when an increasing amount of water, a poor solvent for the polymer samples, is added to the THF solution to induce the formation of aggregates. The PL intensity reaches its maximum at $f_{\mathrm{w}}$ of $80 \%$. The slight drop in the PL intensity at $f_{\mathrm{w}}$ of $90 \%$ is possibly owing to the formation of extensive aggregates to make the suspension unstable and lower the effective solute concentration [68]. P1/2-II shows similar PL behaviors. The PL intensity of P1/2-II starts to rise upon water addition and keeps increasing as the $f_{\mathrm{W}}$ increases to $80 \%$ (Figure $5 \mathrm{c}$ ). The highest PL intensity is attained at $f_{\mathrm{W}}$ of $80 \%$, being about 160 -fold higher than that in pure THF solution (Figure $5 \mathrm{~d}$ ). The dependence of the fluorescence quantum yield $\left(\phi_{\mathrm{F}}\right)$ of P1/2-I and P1/2-II on the solvent composition of the THF/water mixture (Figure S2) also confirmed their AEE characteristics. The dilute THF solutions of P1/2-I and P1/2-II show a low $\phi_{\mathrm{F}}$ of 
$0.8 \%$. With the gradual addition of water, their $\phi_{\mathrm{F}}$ value continuously increase and reach a maximum of $3.1 \%$ and $9.4 \%$, respectively. Nanoaggregates with sizes in the range of 345-271 nm and 323-217 $\mathrm{nm}$ are detected in aqueous solutions of P1/2-I and P1/2-II, respectively (Figures S3 and S4) by dynamic light scattering measurements. The aggregates of P1/2-I and P1/2-II show blue-green emission with emission maximum at around $500 \mathrm{~nm}$.
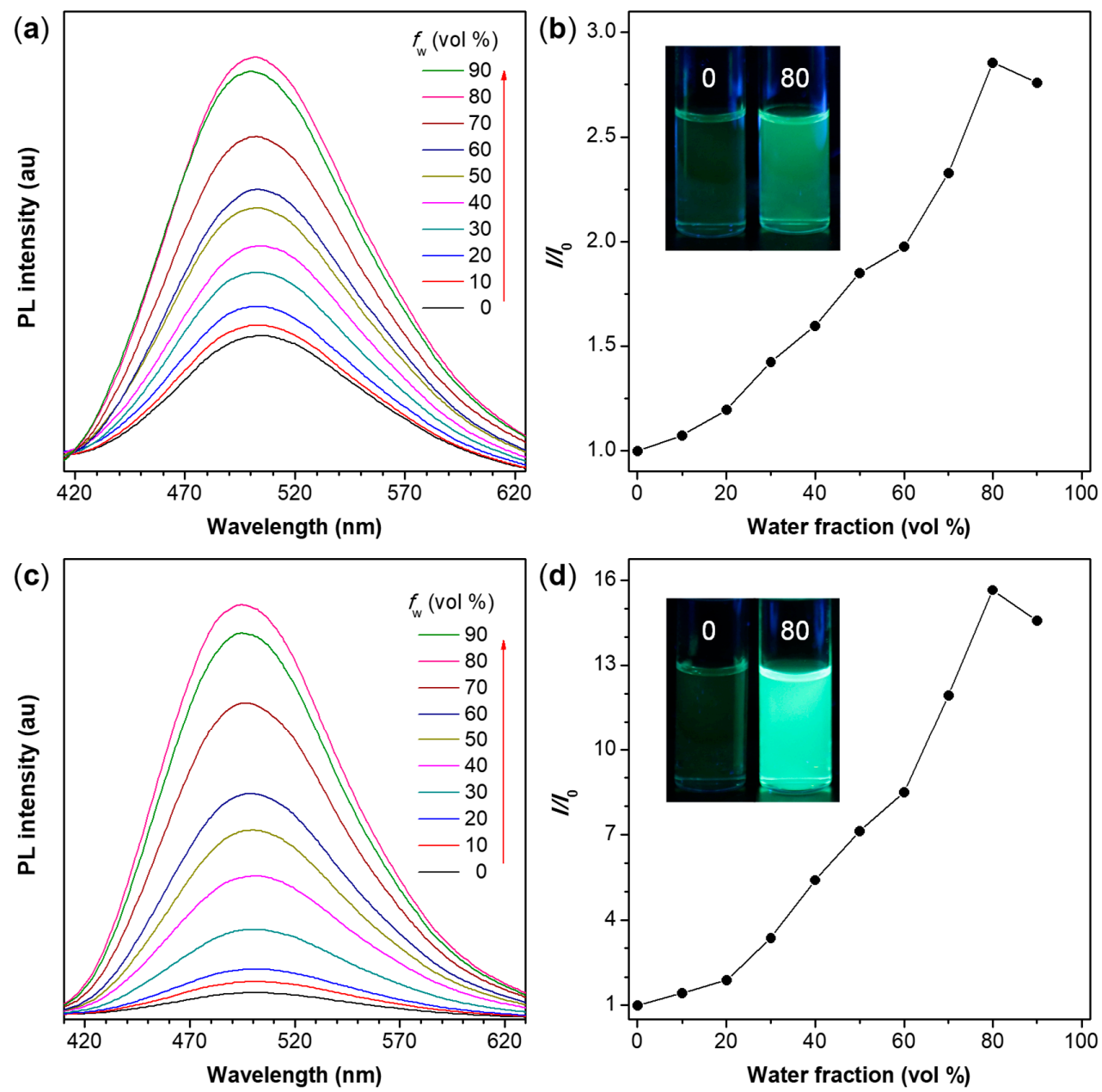

Figure 5. (a,c) PL spectra of (a) P1/2-I and (c) P1/2-II in THF and THF/water mixtures with different water fractions $\left(f_{\mathrm{w}}\right) ;(\mathbf{b}, \mathbf{d})$ Plot of relative emission intensity $\left(I / I_{0}\right)$ versus the composition of the aqueous mixture of (b) P1/2-I and (d) P1/2-II, where $I=$ peak intensity and $I_{0}=$ peak intensity in pure THF solution. Inset: fluorescent photographs of P1/2-I and P1/2-II in pure THF solution and in THF/water mixture with $f_{\mathrm{w}}$ of $80 \%$ taken under $365 \mathrm{~nm}$ UV illumination from a hand-held UV lamp. Solution concentration: $10 \mu \mathrm{M}$; excitation wavelength: $350 \mathrm{~nm}$.

The restriction of intramolecular motion (RIM) has been proposed to be the main cause of the AIE phenomenon of TPE $[62,69]$. Similar to TPE, the RIM mechanism is proposed to play an important role for the AEE properties of P1/2-I and P1/2-II. In the solution state, the phenyl rings in the polymer structures can freely rotate or twist against the ethene stators. Such active intramolecular motions serve as nonradiative channels for the excited state to decay to the ground state to quench the emission. Different from the isolated TPE molecules, the TPE units are covalently linked in the polymer structures and thus the motions of the phenyl rings are restricted to some extent. Therefore, the dilute solutions of P1/2-I and P1/2-II are emissive although the emission is very weak. When the polymers form aggregates in the presence of a large amount of water, the intramolecular motions are further restricted 
due to the involved physical constraint, which blocks the nonradiative relaxation channels and hence enhances the light emission of the polymers.

\subsection{Explosive Detection}

Sensitive detection of nitroaromatic-based explosives, such as picric acid (PA), 2,4-dinitrotoluene and 2,4,6-trinitrotoluene, is of great significance in homeland security and environmental assays and has antiterrorism implications. Fluorescent chemosensors based on AIE-active polymers generally have the advantages of high stability, fast and amplified response, and superior sensitivity to analytes over their small molecular counterparts [65]. They can serve as solid-state detectors or be used in aqueous media without suffering from the problem of analyte-induced self-quenching. To demonstrate the potential of the obtained AIE polymers for explosive detection, picric acid (PA) was selected as a model analyte in this work for its commercial availability. Dispersed nanoaggregates of P1/2-I and P1/2-II were prepared in their THF/water mixtures with $80 \%$ water fraction and used as fluorescent probes. The change in the PL properties of the polymer aggregates in response to PA was quantitively monitored by measuring the PL spectra of the polymer aggregates in the presence of different amounts of PA.

As shown in Figure 6, with the gradual addition of PA into the aqueous mixture of the polymers, the PL intensity of the polymer aggregates decreases progressively while the PL spectral profile remains almost unchanged. At a PA concentration of $0.44 \mathrm{mg} / \mathrm{mL}$, the fluorescence of P1/2-I and P1/2-II is almost completely quenched and their PL intensity $(I)$ decreases by more than $99 \%$ compared with that in the absence of PA $\left(I_{0}\right)$. Different from the conventional linear Stern-Volmer plots of sensors working in solutions [70], the Stern-Volmer plots of the relative PL intensity $\left(I_{0} / I-1\right)$ of P1/2-I and P1/2-II aggregates versus the PA concentration are close to linear at first when the PA concentration is lower than $44 \mu \mathrm{M}$ but subsequently bend upward with the further increase of PA content (Figure $6 \mathrm{~b}, \mathrm{~d}$ ). This result indicates that the quenching process of these two polymer nanoaggregate systems becomes more efficient at higher quencher concentration and shows a superamplification quenching effect [71]. As shown in Figures S5 and S6, large quenching constants $\left(K_{\mathrm{sv}}\right)$ of up to 741,090 and $361,700 \mathrm{M}^{-1}$ are deducted from the Stern-Volmer plots of P1/2-I and P1/2-II, respectively. These values are much higher than those of chemosensors based on polyindole/CdS nanocomposites [72], polysiloles and polygermoles in solutions [73], and small molecules such as benzimidazoliums [74], phthalocyanines [75], and quinoxaline derivatives [76,77], whose $K_{\text {sv }}$ falls in the range of $6710-32,900 \mathrm{M}^{-1}$. According to the equation of $\mathrm{LOD}=3 \mathrm{SB} / \mathrm{m}$, the limit of detection (LOD) values of P1/2-I and P1/2-II aggregates toward PA are calculated to be $2.37 \times 10^{-5}$ and $3.87 \times 10^{-6} \mathrm{M}$, respectively, and are comparable to those of the previous reports [78-80]. The parameter of SB in the aforementioned equation refers to the standard deviation of the blank measurement and $\mathrm{m}$ represents the slope of the linear region of the Stern-Volmer plot [81]. These results demonstrate that the nanoaggregate suspensions of P1/2-I and P1/2-II can be utilized as promising fluorescent chemo-sensors with high sensitivity, amplified response and low detection limit for explosive detection.

To investigate the quenching mechanism, the absorption spectra of PA was measured and compared with the PL spectra of P1/2-I and P1 / 2-II nanoaggregates in 80\% aqueous mixture. As shown in Figure S7, the absorption spectrum of PA is partially overlapped with the PL spectra of the polymer nanoaggregates. This result suggests that effective energy transfer can readily occur from the excited state of the polymer aggregates to the ground state of PA at an appropriate distance to quench the fluorescence of the polymers through nonradiative relaxation process $[82,83]$. Moreover, PA is a typical electron-deficient compound due to its highly nitrated structure, whereas both P1/2-I and P1/2-II possess an electron-rich backbone. The potential involvement of Lewis acid-base interactions between the electron-deficient analytes and the electron-rich polymer chains may also be crucial for this fluorescence quenching phenomenon by orienting the PA molecules in the polymer aggregates in an efficient way for the electron-transfer quenching process $[84,85]$. 

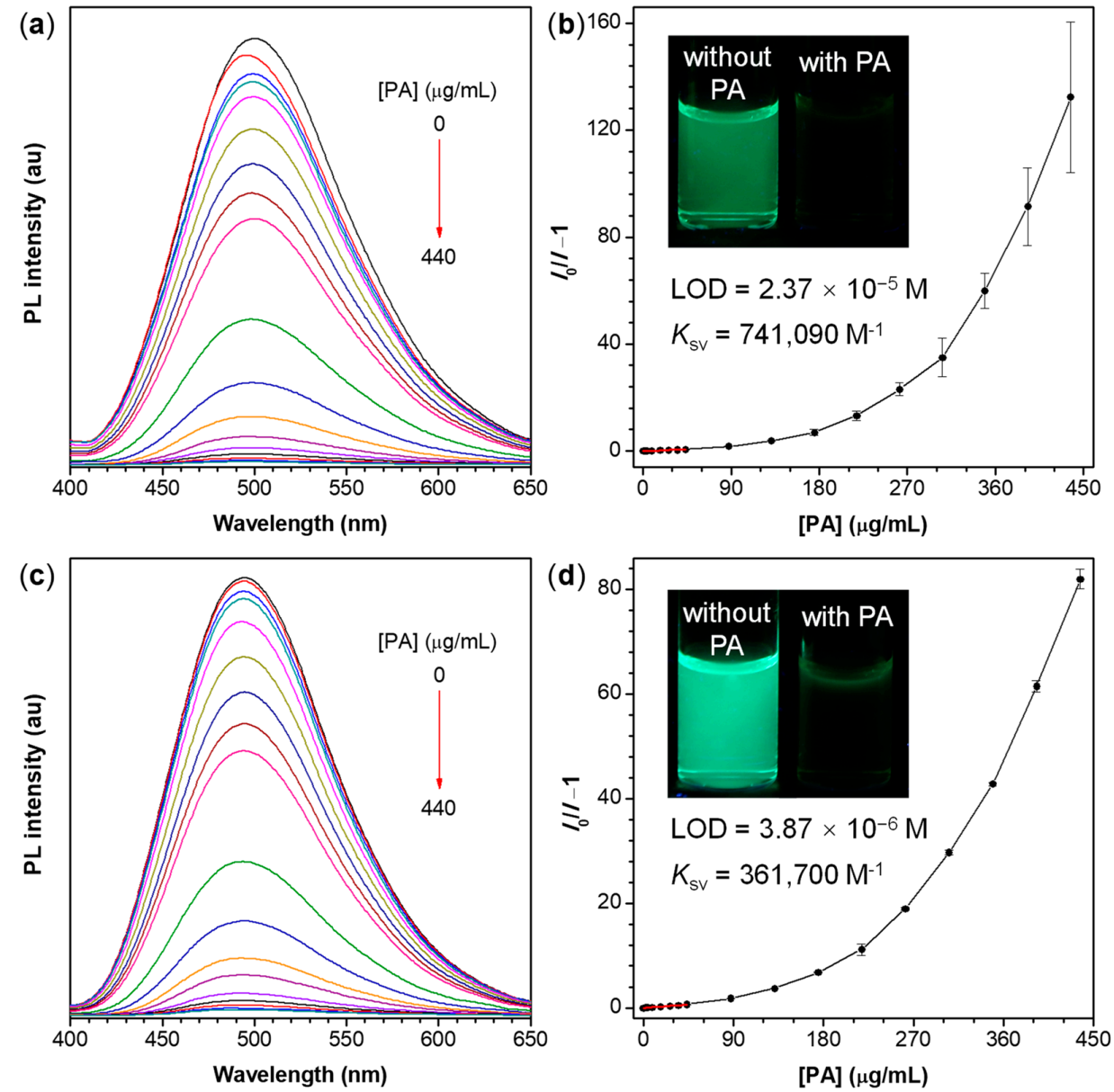

Figure 6. (a,c) PL spectra of (a) P1/2-I and (c) P1/2-II in THF/water mixtures with $80 \%$ water fraction containing different amounts of picric acid (PA); (b,d) Stern-Volmer plots of $\left(I_{0} / I-1\right)$ of $(\mathbf{b})$ P1/2-I and (d) P1/2-II versus the PA concentration, where $I=$ peak intensity and $I_{0}=$ peak intensity without PA. Solution concentration: $10 \mu \mathrm{M}$; excitation wavelength: $350 \mathrm{~nm}$. Inset in panel $(\mathbf{b}$,d): fluorescent photographs of P1/2-I and P1/2-II in THF/water mixture with $f_{\mathrm{w}}$ of $80 \%$ without and with PA taken under $365 \mathrm{~nm}$ UV illumination from a hand-held UV lamp.

With regard to the superamplication quenching effect of the present fluorescent probes, the three-dimensional morphological structures of the polymer nanoaggregates and their AEE features may work collectively to make P1/2-I and P1/2-II highly sensitive to the analytes. Compared with the conventional solution-based sensors, the polymer nanoaggregates in the present sensing systems could bind with more quencher molecules due to the presence of numerous cavities in their three-dimensional morphological structures [68,70]. These three-dimensional cavities can provide additional pathways for the interchain diffusion of excitons and enable the entered quencher molecules like PA to efficiently interact with multiple TPE units in the polymer chains to quench the emission. Moreover, the distinct AEE feature of P1/2-I and P1/2-II endows their nanoaggregates with efficient fluorescence, which can also contribute to the high sensitivitiy [86]. Consequently, the quenching process of the nanoaggregates of these AEE-active polymers is more efficient than conventional solution-based sensors and is highly sensitive to the quencher concentration.

In addition to the "wet" method, we also explored the possibility of using the test strips of P1/2-I and P1/2-II for the PA detection. These polymer-coated strips were fabricated by simply dipping filter paper strips into the polymer solutions [80]. As shown in Figure S8, after solvent evaporation, the obtained test strips exhibit strong fluorescence under $365 \mathrm{~nm}$ UV irradiation from a hand-held UV lamp. When the test strips are partially dipped into the aqueous PA solution, the PA-covered parts 
become almost non-emissive due to the emission quenching by the PA molecules. This result indicates that the explosive detection using the AIE-active P1/2-I and P1/2-II can also be performed in the solid state to facilitate the real-world applications.

\section{Conclusions}

In summary, functional stereoregular polymers with 1,5-dihalo-(Z,Z)-1,4-pentadiene as dominated segments are prepared in this work through the metal-free multicomponent polymerizations of diyne, aldehyde and boron trihalide. The stereoselectivity of the polymerization was demonstrated to be highly dependent on the employed boron trihalide species as well as the reaction conditions. The polymerization of diyne, aldehyde and $\mathrm{BCl}_{3}$ that proceeds at $0{ }^{\circ} \mathrm{C}$ for $1 \mathrm{~h}$ followed by stirring at room temperature for another $1 \mathrm{~h}$ affords poly(dichloropentadiene)s with a predominant $(E, Z)$-configuration. When diyne and $\mathrm{BCl}_{3}$ are allowed to react at $45{ }^{\circ} \mathrm{C}$ for $1 \mathrm{~h}$ prior to further coupling with aldehyde at $0{ }^{\circ} \mathrm{C}$ and room temperature, a high molecular weight polymer (P1/2-I, $\left.M_{\mathrm{w}}=119,700\right)$ with the same composition but mainly $(Z, Z)$-configuration was obtained in a satisfactory yield. The content of $(Z, Z)$-isomeric unit of P1/2-I was determined to be up to 92\%. Replacement of the mediator from $\mathrm{BCl}_{3}$ to $\mathrm{BBr}_{3}$ also results in polymers with a predominant $(Z, Z)-1,4$-pentadiene unit (P1/2-II) in a good yield of $79 \%$ with a high $M_{\mathrm{W}}$ of 63,100 . All the obtained polymers possess good solubility and high thermal stability. The presence of numerous aromatic rings and halogen atoms in the polymer structures endows them with high refractive indices. Together with their good film-forming ability and low optical dispersion, the present polymers are promising to serve as coating materials in advanced photonic devices. The introduction of TPE moiety enables the polymers to show obvious AEE features. The fluorescence of the polymer nanoaggregates in aqueous media can be efficiently quenched by PA with a superamplification effect and a low detection limit, suggesting that they can be used for the sensitive detection of explosives.

Supplementary Materials: The following are available online at http:/ / www.mdpi.com/2073-4360/10/8/821/s1, Scheme S1: synthetic route of P1/2; Figure S1: absorption spectra of P1/2-I and P1/2-II in THF solutions; Figure S2: plot of fluorescence quantum yield of (a) P1/2-I and (b) P1/2-II versus water fraction in THF/water mixtures; Figure S3: particle size distributions of the nanoparticles of P1/2-I measured by dynamic light scattering; Figure S4: particle size distributions of the nanoparticles of P1/2-II measured by dynamic light scattering; Figure S5: fitting curve of P1/2-I for the calculation of the quenching constant; Figure S6: fitting curve of P1/2-II for the calculation of the quenching constant; Figure S7: normalized absorption spectrum of PA in water and PL spectra of P1/2-I and P1/2-II nanoaggregates in THF/water mixtures with 80\% water fraction; Figure S8: fluorescence images of test strips coated with (a) P1/2-I and (b) P1/2-II before and after being partially dipped into an aqueous PA solution.

Author Contributions: T.H. and Y.Z. contributed equally to this work. B.Z.T. and J.W.Y.L. conceived and designed the experiments; T.H. and Y.Z. performed the experiments; T.H., Y.Z. and B.H. analyzed the data; T.H., Y.Z., J.W.Y.L. and B.Z.T. contributed to the writing of this paper.

Funding: This work was supported by the National Science Foundation of China (21788102, 21490570 and 21490574), the Research Grants Council of Hong Kong (16308116, 16303815, 16308016, C6009-17G, and A-HKUST605116), the Innovation and Technology Commission (ITC-CNERC14SC01 and ITS/254/17), the Science and Technology Plan of Shenzhen (JCYJ20160229205601482, JCYJ20160428150429072, and JCYJ20170818113602462) and the International Science \& Technology Cooperation Program of Guangzhou (201704030069).

Conflicts of Interest: The authors declare no conflict of interest.

\section{References}

1. Carraher, C.E. Introduction to Polymer Chemistry; CRC Press: Boca Raton, FL, USA, 2007.

2. Natta, G.; Danusso, F. Stereoregular Polymers and Stereospecific Polymerizations: The Contributions of Giulio Natta and His School to Polymer Chemistry; Elsevier: Atlanta, GA, USA, 2013.

3. Ochiai, B.; Ogihara, T.; Mashiko, M.; Endo, T. Synthesis of rare-metal absorbing polymer by three-component polyaddition through combination of chemo-selective nucleophilic and radical additions. J. Am. Chem. Soc. 2009, 131, 1636-1637. [CrossRef] [PubMed] 
4. Espeel, P.; Goethals, F.; Du Prez, F.E. One-pot multistep reactions based on thiolactones: Extending the realm of thiol-ene chemistry in polymer synthesis. J. Am. Chem. Soc. 2011, 133, 1678-1681. [CrossRef] [PubMed]

5. Blasco, E.; Sims, M.B.; Goldmann, A.S.; Sumerlin, B.S.; Barner-Kowollik, C. 50th anniversary perspective: Polymer functionalization. Macromolecules 2017, 50, 5215-5252. [CrossRef]

6. Bae, I.; Han, H.; Chang, S. Highly efficient one-pot synthesis of N-sulfonylamidines by Cu-catalyzed three-component coupling of sulfonyl azide, alkyne, and amine. J. Am. Chem. Soc. 2005, 127, 2038-2039. [CrossRef] [PubMed]

7. Yoo, E.J.; Bae, I.; Cho, S.H.; Han, H.; Chang, S. A facile access to N-sulfonylimidates and their synthetic utility for the transformation to amidines and amides. Org. Lett. 2006, 8, 1347-1350. [CrossRef] [PubMed]

8. Cho, S.H.; Yoo, E.J.; Bae, L.; Chang, S. Copper-catalyzed hydrative amide synthesis with terminal alkyne, sulfonyl azide, and water. J. Am. Chem. Soc. 2005, 127, 16046-16047. [CrossRef] [PubMed]

9. Kim, S.H.; Park, S.H.; Choi, J.H.; Chang, S. Sulfonyl and phosphoryl azides: Going further beyond the click realm of alkyl and aryl azides. Chem. Asian J. 2011, 6, 2618-2634. [CrossRef] [PubMed]

10. Liu, Y.; Qin, A.J.; Tang, B.Z. Polymerizations based on triple-bond building blocks. Prog. Polym. Sci. 2018, 78, 92-138. [CrossRef]

11. Kakuchi, R. Multicomponent reactions in polymer synthesis. Angew. Chem. Int. Ed. 2014, 53, 46-48. [CrossRef] [PubMed]

12. Hu, R.R.; Li, W.Z.; Tang, B.Z. Recent advances in alkyne-based multicomponent polymerizations. Macromol. Chem. Phys. 2016, 217, 213-224. [CrossRef]

13. Long, Z.; Mao, L.C.; Liu, M.Y.; Wan, Q.; Wan, Y.Q.; Zhang, X.Y.; Wei, Y. Marrying multicomponent reactions and aggregation-induced emission (AIE): New directions for fluorescent nanoprobes. Polym. Chem. 2017, 8, 5644-5654. [CrossRef]

14. Kim, H.; Bang, K.T.; Choi, I.; Lee, J.K.; Choi, T.L. Diversity-oriented polymerization: One-shot synthesis of library of graft and dendronized polymers by $\mathrm{Cu}$-catalyzed multicomponent polymerization. J. Am. Chem. Soc. 2016, 138, 8612-8622. [CrossRef] [PubMed]

15. Zheng, C.; Deng, H.Q.; Zhao, Z.J.; Qin, A.J.; Hu, R.R.; Tang, B.Z. Multicomponent tandem reactions and polymerizations of alkynes, carbonyl chlorides, and thiols. Macromolecules 2015, 48, 1941-1951. [CrossRef]

16. Deng, H.Q.; Hu, R.R.; Zhao, E.G.; Chan, C.Y.K.; Lam, J.W.Y.; Tang, B.Z. One-pot three-component tandem polymerization toward functional poly(arylene thiophenylene) with aggregation-enhanced emission characteristics. Macromolecules 2014, 47, 4920-4929. [CrossRef]

17. Kreye, O.; Toth, T.; Meier, M.A.R. Introducing multicomponent reactions to polymer science: Passerini reactions of renewable monomers. J. Am. Chem. Soc. 2011, 133, 1790-1792. [CrossRef] [PubMed]

18. Sehlinger, A.; Dannecker, P.K.; Kreye, O.; Meier, M.A.R. Diversely substituted polyamides: Macromolecular design using the Ugi four-component reaction. Macromolecules 2014, 47, 2774-2783. [CrossRef]

19. Xue, H.D.; Zhao, Y.; Wu, H.B.; Wang, Z.L.; Yang, B.; Wei, Y.; Wang, Z.M.; Tao, L. Multicomponent combinatorial polymerization via the Biginelli reaction. J. Am. Chem. Soc. 2016, 138, 8690-8693. [CrossRef] [PubMed]

20. Deng, X.X.; Du, F.S.; Li, Z.C. Combination of orthogonal ABB and ABC multicomponent reactions toward efficient divergent synthesis of dendrimers with structural diversity. ACS Macro Lett. 2014, 3, 667-670. [CrossRef]

21. Leitch, D.C.; Kayser, L.V.; Han, Z.Y.; Siamaki, A.R.; Keyzer, E.N.; Gefen, A.; Arndtsen, B.A. A palladium-catalysed multicomponent coupling approach to conjugated poly(1,3-dipoles) and polyheterocycles. Nat. Commun. 2015, 6, 7411. [CrossRef] [PubMed]

22. Liu, Y.J.; Roose, J.; Lam, J.W.Y.; Tang, B.Z. Multicomponent polycoupling of internal diynes, aryl diiodides, and boronic acids to functional poly(tetraarylethene)s. Macromolecules 2015, 48, 8098-8107. [CrossRef]

23. Deng, H.Q.; Zhao, E.G.; Li, H.K.; Lam, J.W.Y.; Tang, B.Z. Multifunctional poly(N-sulfonylamidine)s constructed by $\mathrm{Cu}$-catalyzed three-component polycouplings of diynes, disulfonyl azide, and amino esters. Macromolecules 2015, 48, 3180-3189. [CrossRef]

24. Lee, I.H.; Kim, H.; Choi, T.L. Cu-catalyzed multicomponent polymerization to synthesize a library of poly(N-sulfonylamidines). J. Am. Chem. Soc. 2013, 135, 3760-3763. [CrossRef] [PubMed]

25. Zhang, Z.; You, Y.Z.; Wu, D.C.; Hong, C.Y. Syntheses of sequence-controlled polymers via consecutive multicomponent reactions. Macromolecules 2015, 48, 3414-3421. [CrossRef] 
26. Kim, H.; Choi, T.L. Preparation of a library of poly( $N$-sulfonylimidates) by Cu-catalyzed multicomponent polymerization. ACS Macro Lett. 2014, 3, 791-794. [CrossRef]

27. Deng, H.Q.; Han, T.; Zhao, E.G.; Kwok, R.T.K.; Lam, J.W.Y.; Tang, B.Z. Multicomponent polymerization: Development of a one-pot synthetic route to functional polymers using diyne, $N$-sulfonyl azide and water/ethanol as reactants. Polym. Chem. 2016, 7, 5646-5654. [CrossRef]

28. Deng, H.Q.; Han, T.; Zhao, E.G.; Kwok, R.T.K.; Lam, J.W.Y.; Tang, B.Z. Multicomponent click polymerization: A facile strategy toward fused heterocyclic polymers. Macromolecules 2016, 49, 5475-5483. [CrossRef]

29. Xu, L.G.; Hu, R.R.; Tang, B.Z. Room temperature multicomponent polymerizations of alkynes, sulfonyl azides, and iminophosphorane toward heteroatom-rich multifunctional poly(phosphorus amidine)s. Macromolecules 2017, 50, 6043-6053. [CrossRef]

30. Xu, L.G.; Zhou, F.; Liao, M.; Hu, R.R.; Tang, B.Z. Room temperature multicomponent polymerizations of alkynes, sulfonyl azides, and $N$-protected isatins toward oxindole-containing poly( $N$-acylsulfonamide)s. Polym. Chem. 2018, 9, 1674-1683. [CrossRef]

31. Wei, B.; Li, W.Z.; Zhao, Z.J.; Qin, A.J.; Hu, R.R.; Tang, B.Z. Metal-free multicomponent tandem polymerizations of alkynes, amines, and formaldehyde toward structure- and sequence-controlled luminescent polyheterocycles. J. Am. Chem. Soc. 2017, 139, 5075-5084. [CrossRef] [PubMed]

32. Karpov, A.S.; Muller, T.J.J. Straightforward novel one-pot enaminone and pyrimidine syntheses by coupling-addition-cyclocondensation sequences. Synthesis 2003, 2003, 2815-2826. [CrossRef]

33. Karpov, A.S.; Muller, T.J.J. New entry to a three-component pyrimidine synthesis by TMS-ynones via Sonogashira coupling. Org. Lett. 2003, 5, 3451-3454. [CrossRef] [PubMed]

34. Pohlki, F.; Doye, S. The catalytic hydroamination of alkynes. Chem. Soc. Rev. 2003, 32, 104-114. [CrossRef] [PubMed]

35. Muller, T.E.; Hultzsch, K.C.; Yus, M.; Foubelo, F.; Tada, M. Hydroamination: Direct addition of amines to alkenes and alkynes. Chem. Rev. 2008, 108, 3795-3892. [CrossRef] [PubMed]

36. Severin, R.; Doye, S. The catalytic hydroamination of alkynes. Chem. Soc. Rev. 2007, 36, 1407-1420. [CrossRef] [PubMed]

37. Deng, H.Q.; He, Z.K.; Lam, J.W.Y.; Tang, B.Z. Regio- and stereoselective construction of stimuli-responsive macromolecules by a sequential coupling-hydroamination polymerization route. Polym. Chem. 2015, 6, 8297-8305. [CrossRef]

38. Deng, H.Q.; Hu, R.R.; Leung, A.C.S.; Zhao, E.G.; Lam, J.W.Y.; Tang, B.Z. Construction of regio- and stereoregular poly(enaminone)s by multicomponent tandem polymerizations of diynes, diaroyl chloride and primary amines. Polym. Chem. 2015, 6, 4436-4446. [CrossRef]

39. Kabalka, G.W.; Wu, Z.Z.; Ju, Y.H. A new reaction of aryl aldehydes with aryl acetylenes in the presence of boron trihalides. Org. Lett. 2002, 4, 1491-1493. [CrossRef] [PubMed]

40. Kabalka, G.W.; Yao, M.L.; Borella, S.; Wu, Z.Z.; Ju, Y.H.; Quick, T. Boron trihalide mediated alkyne-aldehyde coupling reactions: A mechanistic investigation. J. Org. Chem. 2008, 73, 2668-2673. [CrossRef] [PubMed]

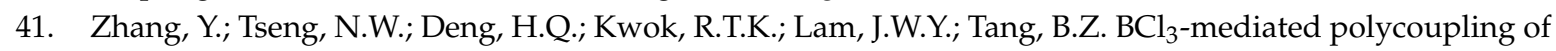
alkynes and aldehydes: A facile, metal-free multicomponent polymerization route to construct stereoregular functional polymers. Polym. Chem. 2016, 7, 4667-4674. [CrossRef]

42. Wu, H.Q.; Li, H.K.; Kwok, R.T.K.; Zhao, E.G.; Sun, J.Z.; Qin, A.J.; Tang, B.Z. A recyclable and reusable supported $\mathrm{Cu}(\mathrm{I})$ catalyzed azide-alkyne click polymerization. Sci. Rep. 2014, 4, 5107. [CrossRef] [PubMed]

43. Lansinger, J.M.; Ronald, R.C. Reactions of aromatic aldehydes with boron halides. Synth. Commun. 1979, 9, 341-349. [CrossRef]

44. Si, J.J.; Xu, P.J.; He, W.; Wang, S.J.; Jing, X.L. Bis-benzoxazine resins with high char yield and toughness modified by hyperbranched poly(resorcinol borate). Compos. Part A Appl. Sci. Manuf. 2012, 43, 2249-2255. [CrossRef]

45. Li, X.G.; Huang, M.R.; Bai, H.; Yang, Y.L. Thermogravimetry of thermoplastic polyimide powders under four different atmospheres. Macromol. Mater. Eng. 2001, 286, 421-428. [CrossRef]

46. Sydlik, S.A.; Chen, Z.H.; Swager, T.M. Triptycene polyimides: Soluble polymers with high thermal stability and low refractive indices. Macromolecules 2011, 44, 976-980. [CrossRef]

47. Liu, J.G.; Ueda, M. High refractive index polymers: Fundamental research and practical applications. J. Mater. Chem. 2009, 19, 8907-8919. [CrossRef] 
48. Higashihara, T.; Ueda, M. Recent progress in high refractive index polymers. Macromolecules 2015, 48, 1915-1929. [CrossRef]

49. Brandrup, J.; Immergut, E.H.; Gruike, E.A. Polymer Handbook, 4th ed.; Wiley: New York, NY, USA; Chichester, UK, 2004.

50. Javadi, A.; Abouzari-Lotf, E.; Mehdipour-Ataei, S.; Zakeri, M.; Nasef, M.M.; Ahmad, A.; Ripin, A. High refractive index materials: A structural property comparison of sulfide- and sulfoxide-containing polyamides. J. Polym. Sci. Polym. Chem. 2015, 53, 2867-2877. [CrossRef]

51. Nakabayashi, K.; Imai, T.; Fu, M.C.; Ando, S.; Higashihara, T.; Ueda, M. Poly(phenylene thioether)s with fluorene-based cardo structure toward high transparency, high refractive index, and low birefringence. Macromolecules 2016, 49, 5849-5856. [CrossRef]

52. Hecht, E. Optics, 4th ed.; Addison Wesley: San Francisco, CA, USA, 2002.

53. Matsuda, T.; Funae, Y.; Yoshida, M.; Yamamoto, T.; Takaya, T. Optical material of high refractive index resin composed of sulfur-containing aromatic methacrylates. J. Appl. Polym. Sci. 2000, 76, 50-54. [CrossRef]

54. Huang, S.H.; Chiang, Y.W.; Hong, J.L. Luminescent polymers and blends with hydrogen bond interactions. Polym. Chem. 2015, 6, 497-508. [CrossRef]

55. Yu, J.B.; Rong, Y.; Kuo, C.T.; Zhou, X.H.; Chiu, D.T. Recent advances in the development of highly luminescent semiconducting polymer dots and nanoparticles for biological imaging and medicine. Anal. Chem. 2017, 89, 42-56. [CrossRef] [PubMed]

56. Wu, C.F.; Chiu, D.T. Highly fluorescent semiconducting polymer dots for biology and medicine. Angew. Chem. Int. Ed. 2013, 52, 3086-3109. [CrossRef] [PubMed]

57. Breul, A.M.; Hager, M.D.; Schubert, U.S. Fluorescent monomers as building blocks for dye labeled polymers: Synthesis and application in energy conversion, biolabeling and sensors. Chem. Soc. Rev. 2013, 42, 5366-5407. [CrossRef] [PubMed]

58. Chi, Z.G.; Zhang, X.Q.; Xu, B.J.; Zhou, X.; Ma, C.P.; Zhang, Y.; Liu, S.W.; Xu, J.R. Recent advances in organic mechanofluorochromic materials. Chem. Soc. Rev. 2012, 41, 3878-3896. [CrossRef] [PubMed]

59. Sekine, C.; Tsubata, Y.; Yamada, T.; Kitano, M.; Doi, S. Recent progress of high performance polymer OLED and OPV materials for organic printed electronics. Sci. Technol. Adv. Mater. 2014, 15, 0324203. [CrossRef] [PubMed]

60. Birks, J.B. Photophysics of Aromatic Molecules; Wiley: London, UK, 1970.

61. Luo, J.D.; Xie, Z.L.; Lam, J.W.Y.; Cheng, L.; Chen, H.Y.; Qiu, C.F.; Kwok, H.S.; Zhan, X.W.; Liu, Y.Q.; Zhu, D.B.; et al. Aggregation-induced emission of 1-methyl-1,2,3,4,5-pentaphenylsilole. Chem. Commun. 2001, 1740-1741. [CrossRef]

62. Mei, J.; Leung, N.L.C.; Kwok, R.T.K.; Lam, J.W.Y.; Tang, B.Z. Aggregation-induced emission: Together we shine, united we soar! Chem. Rev. 2015, 115, 11718-11940. [CrossRef] [PubMed]

63. Yang, J.; Li, L.; Yu, Y.; Ren, Z.C.; Peng, Q.; Ye, S.H.; Li, Q.Q.; Li, Z. Blue pyrene-based AIEgens: Inhibited intermolecular $\pi-\pi$ stacking through the introduction of substituents with controllable intramolecular conjugation, and high external quantum efficiencies up to $3.46 \%$ in non-doped OLEDs. Mater. Chem. Front. 2017, 1, 91-99. [CrossRef]

64. Wu, W.B.; Ye, S.H.; Huang, L.J.; Xiao, L.; Fu, Y.J.; Huang, Q.; Yu, G.; Liu, Y.Q.; Qin, J.G.; Li, Q.Q.; et al. A conjugated hyperbranched polymer constructed from carbazole and tetraphenylethylene moieties: Convenient synthesis through one-pot " $\mathrm{A}_{2}+\mathrm{B}_{4}$ " Suzuki polymerization, aggregation-induced enhanced emission, and application as explosive chemosensors and PLEDs. J. Mater. Chem. 2012, 22, 6374-6382. [CrossRef]

65. Hu, R.R.; Leung, N.L.C.; Tang, B.Z. AIE macromolecules: Syntheses, structures and functionalities. Chem. Soc. Rev. 2014, 43, 4494-4562. [CrossRef] [PubMed]

66. Pucci, A.; Rausa, R.; Ciardelli, F. Aggregation-induced luminescence of polyisobutene succinic anhydrides and imides. Macromol. Chem. Phys. 2008, 209, 900-906. [CrossRef]

67. Zhao, Z.J.; Lam, J.W.Y.; Tang, B.Z. Tetraphenylethene: A versatile AIE building block for the construction of efficient luminescent materials for organic light-emitting diodes. J. Mater. Chem. 2012, 22, 23726-23740. [CrossRef]

68. Liu, Y.J.; Gao, M.; Lam, J.W.Y.; Hu, R.R.; Tang, B.Z. Copper-catalyzed polycoupling of diynes, primary amines, and aldehydes: A new one-pot multicomponent polymerization tool to functional polymers. Macromolecules 2014, 47, 4908-4919. [CrossRef] 
69. Mei, J.; Hong, Y.N.; Lam, J.W.Y.; Qin, A.J.; Tang, Y.H.; Tang, B.Z. Aggregation-induced emission: The whole is more brilliant than the parts. Adv. Mater. 2014, 26, 5429-5479. [CrossRef] [PubMed]

70. Liu, J.Z.; Zhong, Y.C.; Lam, J.W.Y.; Lu, P.; Hong, Y.N.; Yu, Y.; Yue, Y.N.; Faisal, M.; Sung, H.H.Y.; Williams, I.D.; et al. Hyperbranched conjugated polysiloles: Synthesis, structure, aggregation-enhanced emission, multicolor fluorescent photopatterning, and superamplified detection of explosives. Macromolecules 2010, 43, 4921-4936. [CrossRef]

71. Liu, J.Z.; Zhong, Y.C.; Lu, P.; Hong, Y.N.; Lam, J.W.Y.; Faisal, M.; Yu, Y.; Wong, K.S.; Tang, B.Z. A superamplification effect in the detection of explosives by a fluorescent hyperbranched poly(silylenephenylene) with aggregation-enhanced emission characteristics. Polym. Chem. 2010, 1, 426-429. [CrossRef]

72. Faraz, M.; Shakir, M.; Khare, N. Highly sensitive and selective detection of picric acid using a one pot biomolecule inspired polyindole/CdS nanocomposite. New J. Chem. 2017, 41, 5784-5793. [CrossRef]

73. Sohn, H.; Sailor, M.J.; Magde, D.; Trogler, W.C. Detection of nitroaromatic explosives based on photoluminescent polymers containing metalloles. J. Am. Chem. Soc. 2003, 125, 3821-3830. [CrossRef] [PubMed]

74. Joshi, S.; Kumari, S.; Chamorro, E.; Pant, D.D.; Sakhuja, R. Fluorescence quenching of a benzimidazolium-based probe for selective detection of picric acid in aqueous medium. ChemistrySelect 2016, 1, 1756-1762. [CrossRef]

75. Gupta, A.; Kang, Y.A.; Choi, M.S.; Park, J.S. Characteristic response of tetra(methylbenzyloxy)-substituted zinc-phthalocyanine toward picric acid. Sens. Actuators B Chem. 2015, 209, 225-229. [CrossRef]

76. Mazumdar, P.; Maity, S.; Shyamal, M.; Das, D.; Sahoo, G.P.; Misra, A. Proton triggered emission and selective sensing of picric acid by the fluorescent aggregates of 6,7-dimethyl-2,3-bis-(2-pyridyl)-quinoxaline. Phys. Chem. Chem. Phys. 2016, 18, 7055-7067. [CrossRef] [PubMed]

77. Li, K.; Yu, R.H.; Shi, C.M.; Tao, F.R.; Li, T.D.; Cui, Y.Z. Electrospun nanofibrous membrane based on AIE-active compound for detecting picric acid in aqueous solution. Sens. Actuators B Chem. 2018, 262, 637-645. [CrossRef]

78. Pinrat, O.; Boonkitpatarakul, K.; Paisuwan, W.; Sukwattanasinitt, M.; Ajavakom, A. Glucopyranosyl-1,4-dihydropyridine as a new fluorescent chemosensor for selective detection of 2,4,6-trinitrophenol. Analyst 2015, 140, 1886-1893. [CrossRef] [PubMed]

79. Ma, Y.X.; Li, H.; Peng, S.; Wang, L.Y. Highly selective and sensitive fluorescent paper sensor for nitroaromatic explosive detection. Anal. Chem. 2012, 84, 8415-8421. [CrossRef] [PubMed]

80. He, B.Z.; Su, H.F.; Bai, T.W.; Wu, Y.W.; Li, S.W.; Gao, M.; Hu, R.R.; Zhao, Z.J.; Qin, A.J.; Ling, J.; et al. Spontaneous amino-yne click polymerization: A powerful tool toward regio- and stereospecific poly( $\beta$-aminoacrylate)s. J. Am. Chem. Soc. 2017, 139, 5437-5443. [CrossRef] [PubMed]

81. He, B.Z.; Wu, Y.W.; Qin, A.J.; Tang, B.Z. Copper-catalyzed electrophilic polyhydroamination of internal alkynes. Macromolecules 2017, 50, 5719-5728. [CrossRef]

82. Wang, J.; Mei, J.; Yuan, W.Z.; Lu, P.; Qin, A.J.; Sun, J.Z.; Ma, Y.G.; Tang, B.Z. Hyperbranched polytriazoles with high molecular compressibility: Aggregation-induced emission and superamplified explosive detection. J. Mater. Chem. 2011, 21, 4056-4059. [CrossRef]

83. Franzen, S.; Ni, W.J.; Wang, B.H. Study of the mechanism of electron-transfer quenching by boron-nitrogen adducts in fluorescent sensors. J. Phys. Chem. B 2003, 107, 12942-12948. [CrossRef]

84. Gao, M.X.; Wu, Y.; Chen, B.; He, B.R.; Nie, H.; Li, T.Y.; Wu, F.P.; Zhou, W.J.; Zhou, J.; Zhao, Z.J. Di(naphthalen-2-yl)-1,2-diphenylethene-based conjugated polymers: Aggregation-enhanced emission and explosive detection. Polym. Chem. 2015, 6, 7641-7645. [CrossRef]

85. Sanchez, J.C.; DiPasquale, A.G.; Mrse, A.A.; Trogler, W.C. Lewis acid-base interactions enhance explosives sensing in silacycle polymers. Anal. Bioanal. Chem. 2009, 395, 387-392. [CrossRef] [PubMed]

86. Gao, M.; Lam, J.W.Y.; Li, J.; Chan, C.Y.K.; Chen, Y.L.; Zhao, N.; Han, T.Y.; Tang, B.Z. Stoichiometric imbalance-promoted synthesis of polymers containing highly substituted naphthalenes: Rhodium-catalyzed oxidative polycoupling of arylboronic acids and internal diynes. Polym. Chem. 2013, 4, 1372-1380. [CrossRef]

(C) 2018 by the authors. Licensee MDPI, Basel, Switzerland. This article is an open access article distributed under the terms and conditions of the Creative Commons Attribution (CC BY) license (http:/ / creativecommons.org/licenses/by/4.0/). 